\title{
DE CAMINO A DES-OCULTAR LO EVIDENTE: ACERCA DEL ENJAMBRE DIGITAL
}

\author{
On the way to un-cover the obvious: about the digital swarm
}

\section{RESUMEN}

La construcción social del espacio implica un proceso de constante resemantización que se configura bajo la égida de la cultura dominante o de formas de vida alternativas/alterativas en juego dialéctico. En otras palabras, las relaciones sociales operantes en cada sociedad y tiempo histórico se objetivan en una trama de voces heterogéneas e incluso opuestas. Este proceso afecta tanto al espacio físico o territorio como al espacio o enjambre digital. El propósito de este artículo es confrontar algunas hipótesis acerca del enjambre digital provenientes de la Sociología, la Filosofía, los Estudios Culturales y la Geocrítica, con el fin de problematizar o deconstruir algunas creencias y saberes relativos a este nuevo ámbito humano de circulación de los discursos y, en consecuencia, de determinación e indeterminación de las identidades.

Palabras claves: Geocrítica - espacio digital enjambre - sociedad - identidad

\section{UNIVERSUM}

Revista de Humanidades y Ciencias Sociales

\section{ROSSANA}

SCARICABAROZZI

Facultad de Ciencias Sociales, Universidad Católica Argentina, Argentina.

Correo electrónico:

r_scaricabarozzi@uca.edu.ar

ORCID: 0000-0002-8244-067X

ResearchGate:

Scholar.google:

Academia.edu: 


\begin{abstract}
The social construction of space implies a process of constant resemantization that is configured under the aegis of the dominant culture or of alternative / alterative life forms in dialectical play. In other words, the social relations operating in each society and historical time are objectified in a plot of heterogeneous and even opposite voices. This process affects both the physical space or territory and the digital space or swarm. The purpose of this article is to confront some hypotheses about the digital swarm from Sociology, Philosophy, Cultural Studies and Geocriticism, in order to problematize or deconstruct certain beliefs about this new human sphere of circulation of discourses and, consequently, of identity determination and indeterminacy.
\end{abstract}

Keywords: Geocriticism - digital space - swarm - society - identity

Por el espacio, el universo me comprende y me devora como a un punto; por el pensamiento, yo lo comprendo.

Blas Pascal

\title{
ALGUNAS APROXIMACIONES A LOS CONCEPTOS DE ESPACIO Y ENJAMBRE DIGITAL
}

La pretensión de mostrar el espacio por el espacio mismo constituye, según Lefebvre (2013), una repetición inútil y viciosa, pues en su carácter de práctica social es distinto de la representación exacta de la cosa. Explica el autor francés que todo espacio humano es producto de un conjunto de relaciones sociales cuya producción solo puede atribuirse a una sociedad determinada. Asimismo, Yin-Fu Tuan destaca en su Topofilia que toda cosmovisión se crea "necesariamente a partir de los factores preponderantes de la realidad física y social" en la que están inmersos los sujetos (Tuan, 2007: 112).

En su condición de integrante del mundo social, el espacio es una suerte de entramado con límites más o menos establecidos que contiene objetos heterogéneos tanto naturales como sociales, incluyendo redes y ramificaciones facilitadoras del intercambio de artículos e informaciones (Lefebvre, 2013; Bourdieu, 2019). Los lazos sociales ponen de manifiesto la relación de identidad Nosotros-Ellos, vínculo social en el que cada Nosotros 
naturaliza o está convencido de que su manera de percibir al Ellos -u Otro- es la verdadera.

El espacio social aparece entonces en el mundo de la vida cotidiana bajo la forma de perspectivas diversas atravesadas por la historia. En efecto, el tiempo y el espacio no son coordenadas disociadas, sino que este último implica un tiempo y viceversa. La diferenciación abstracta entre ambos, señala Lefebvre (2013), no les es propia. En tal sentido, Bertrand Westphal afirma que:

Todo espacio se despliega a la vez en la duración y en el instante, y como es rico en virtualidades, se abre si no sobre muchas duraciones, al menos sobre una pluralidad de instantes concomitantes. Esto significa que si el espacio es móvil, lo es esencialmente en el tiempo. (...) Así, el espacio es emergencia constante; está tomado por un movimiento perpetuo de reterritorialización (Westphal, 2015: 41-42).

Al igual que el espacio, el tiempo parece señalar la evidencia pero, sin embargo, se topa con ella. Cada sociedad desarrolla su propia concepción temporal. Entre los kichwa canelos de la Amazonia ecuatoriana, por caso, el sentido del tiempo "no reproduce una comprensión cronológica y consecutiva de los 'tiempos que pasan' ni de un futuro inédito - o como repetición del presente - al cual dirigirse de forma programada o planificada" (Martínez Novo, 2012: 115). Los chinos, por su parte, no construyen socialmente el tiempo en términos cuánticos sino en relación con dos estaciones claves que conforman una unidad: lo que dejamos y lo que viene (Jullien 2005). Dicho de otro modo, para los orientales el ser es siempre ser en fase, en duración. Y todo es una especie de unidad procesual. En consecuencia, el cambio no se pone de manifiesto frente a una aparente ruptura, como sucede en la comunidad occidental, sino que es una expresión de sutiles transformaciones silenciosas (Jullien, 2010).

Siguiendo a Rüdiger Safranski (2017), es posible afirmar que el espacio, al igual que el tiempo, constituye la experiencia resultante de una introyección normativizada y resignificada. Esta última es llevada a cabo 
por el actor social a través de los procesos de socialización que transita en determinadas circunstancias socio-históricas.

Desde la mirada de Henri Lefebvre, el espacio oculta lo que contiene bajo sus significaciones y emerge en toda su diferencia a la manera de una estructura de "mil hojas", superando, de esa forma, la isotropía propia del espacio matemático euclidiano-cartesiano. En rigor, no descarta la relación dialéctica de "producción-consumo" aplicada a los "bienes, mercancías y objetos de cambio", pero la altera sensiblemente ampliándola (Lefebvre, 2013: 141). El filósofo francés se pregunta cuántos mapas serían necesarios para cifrar o descifrar todos los sentidos y contenidos operantes en dicha complejidad. Más aún, atendiendo a que el espacio vive a través de los "deslizamientos de sentido" que lo atraviesan perpetuamente (Westphal, 2015: 36).

La cuestión radica en pensar cómo el espacio nace y se desarrolla a través del tiempo y de las sociedades particulares, de tal manera que es una idea que siempre está en construcción. De lo que se trata es de sustituir la simple consideración de una categoría a primera vista "natural" por otra susceptible de ser problematizada. Es preciso, entonces, descorrer los velos de la realidad social con el fin de descubrir los intercambios y las mediaciones sociales implicadas. Pues debajo de la superficie de la evidencia, el espacio humano se constituye como una trama capaz de vehiculizar diversos modos de estar en el mundo (Rawls, 1993). De ahí que no sea posible abordarlo sin recurrir a diferentes dominios del saber.

En este trabajo plantearemos una primera aproximación al espacio digital en diálogo con la Geocrítica, perspectiva interdisciplinaria que se propone contribuir a la deconstrucción del espacio en tanto ámbito de circulación de discursos y, por tal motivo, íntimamente ligado a la determinación o indeterminación de la identidad social y personal (Westphal, 2015, 2016). Partiremos de una visión autopoiética de la sociedad -defendida por autores como Peter L. Berger y Thomas Luckmann (2015), Cornelius Castoriadis (1993), Pierre Bourdieu (2011, 2019), Jürgen Habermas (1993), Anthony Giddens y Philip W. Sutton (2018), entre otros-, entendiendo que 
las relaciones sociales operantes en el espacio digital resultan de procesos de creación social y personal, establecidos en el contacto humano cara a cara y en diálogo con interdependencias más amplias. ${ }^{1}$

La acción humana es capaz de creaciones sociales marcadamente diversas (Giddens 2011, 2018), incluso algunas tan eficaces como el lenguaje. Su producción puede realizarse de forma independiente de lo sólidamente establecido y a pesar de que los hechos sociales pueden determinar nuestras acciones. Todo ello acontece en una mezcla de dominación/resistencia, opuestos/no-opuestos, caos/cosmos/, etcétera. Así, se trata de indagar, en la línea de Alfred Schütz y Thomas Luckmann (2015), Ludwig Wittgenstein (2003), Michel de Certeau (1990), Stuart Hall (1996, 2017) y Philippe Corcuff (2015), la composibilidad de diversas formas de vida que integran el territorio discursivo digital. Tal como afirma Bertrand Westphal, es preciso "delinear nuevos espacios de lo posible (...) a fin de dejar emerger sus potencialidades" (2015: 246). Esto sin perder de vista que el espacio se sitúa en la confrontación con dos elementos clave en toda relación social: sus "estratos temporales" y la “composibilidad de mundos" que abre (41).

Este recorrido hermenéutico pondrá de manifiesto la existencia de un espacio que debe ser concebido desde otros "relatos de espacio" por fuera del hegemónico, aunque sin ignorar su influencia y, de tal manera, reconocer la facultad creadora y recreadora del ser humano en toda su complejidad (de Certeau, 1990: 170). La hipótesis que guía nuestro trabajo puede formularse del siguiente modo: el territorio digital o enjambre, término popularizado por el filósofo Byung-Chul Han (2014), no constituye solo una expresión de la cultura dominante sino también de otros sentidos innúmeros subculturales o contraculturales, socio-individualmente construidos en un ámbito particular y en un tiempo histórico determinado. En términos de la Geocrítica, no se

\footnotetext{
1 Resulta oportuno aclarar que la presente propuesta no supera los programas individuales, holistas ni relacionistas, sino que, más modestamente, pretende explorar el enjambre digital desde la complejidad propia de la vida social, sin que lo individual o lo colectivo se ubiquen en primer plano y sin presuponer que los comportamientos sociales sean solo una expresión de la cultura dominante $\mathrm{o}$, por el contrario, se pretendan ingenuamente libres.
} 
trata de una relación social unilateral (espacio digital-discursos circulantes), sino de una verdadera dialéctica (espacio digital-discursos circulantes-espacio digital). Esto se explica por el hecho de que el espacio se transforma en función de los diferentes discursos previamente construidos y asimilados a él.

De lo dicho hasta aquí se desprenden algunos interrogantes: ¿cuáles son los componentes que intervienen en la conformación del espacio digital? ¿Es posible tratarlo como si se tratara de un mundo de significaciones autónomo o se funda prioritariamente en los mecanismos de dominación social? O, al contrario, ¿es un espacio dialógico donde se entremezclan expresiones propias de la cultura hegemónica y otras capaces de transformaciones socio-personales e históricas?

La tarea consiste en repensar, primero, si estamos frente a una "topología" del todo distinta. Al respecto, Byung-Chul Han sostiene que al enjambre le son ajenos

los lugares de congregación de masas. Los habitantes digitales de la red no se congregan. Les falta la intimidad de la congregación, que produciría un nosotros. Constituyen una concentración sin congregación, una multitud sin interioridad, un conjunto sin alma o espíritu. (Han, 2014: 17)

Según el autor surcoreano, el enjambre funda una muchedumbre constituida por individuos interconectados en virtud de las nuevas tecnologías, pero que, al mismo tiempo, no pueden componer una unidad galvanizada capaz de transformaciones sociales. Más aún, los seres humanos digitales son "hikikomoris": personas que permanecen al margen de la sociedad, aisladas ante el monitor y que parecen disfrutar de una libertad ilimitada. $\mathrm{Y}$ aunque a veces aparentan configurarse como colectivos con una mística aglutinante, son marcadamente fugaces e inestables. Así es que el intercambio de mensajes (o comportamiento) de los sujetos en este ámbito digital 
Destruye el espacio público y agudiza el aislamiento del hombre. Lo que domina la comunicación digital no es el 'amor al prójimo', sino el narcicismo. La técnica digital no es una 'tánica del amor al prójimo'. Se muestra como una máquina narcisista del ego. Y no es ningún medio dialogístico. (Han, 2014: 53)

La perspectiva de Han da cuenta de que el giro digital abrió paso a otro mundo de vida de presente permanente, a-cultural y desalmado. $\mathrm{Y}$ a pesar de que reconoce que los nuevos medios son admirables, también asegura que son capaces de destruir el canal de comunicación del espíritu: el silencio. De esta forma, el lenguaje y la cultura se vulgarizan y degradan sin cesar (Han, 2014: 26). Más aún, los individuos representan modelos de autoexplotación del sistema o explotación sin dominio (Han, 2017). En términos de la dialéctica propuesta por Theodor Ludwig W. Adorno y Max Horkheimer (2007), son sujetos/objetos que se creen libres sin serlo dado que sus formas de vida no hacen otra cosa que reproducir los andamiajes de dominación del sistema.

En la vereda opuesta de Han, Michael Hardt y Toni Negri (2004) señalan que el enjambre se halla integrado por una "cybermultitud", expresión esta última que designa una multiplicidad actuante de manera organizada. Además, sus miembros son rebeldes a las fuerzas normalizadoras del espacio digital, conscientes de su capacidad creadora, y decisivos para desafiar las representaciones hegemónicas.

El supuesto quiebre ontológico producido por la denominada revolución digital, que transfigura en un enjambre diferentes formas de agrupación humana, también es cuestionado por Vicente Ordoñez Roig (2018), quien advierte que el espacio digital es mucho más complejo que la descripción ofrecida por ciertas perspectivas apocalípticas. En consecuencia, el autor se rehúsa a concebir dicho espacio como únicamente integrado por usuarios individualistas a ultranza, cegados por pulsiones hedonistas que se traducen, de modo recurrente, en un mero me gusta. En favor de su posición, recuerda que en el último decenio hemos asistido a revueltas instrumentadas por las tecnologías digitales en aras de una mayor organización y cohesión; así menciona ejemplos tales como "los disturbios de los trabajadores de la Tonghua Iron and Steel Group" en China, los movimientos ciudadanos de 
"la Primavera Árabe tunecina" o "la campaña a favor del Brexit", entre otros (Ordoñez Roig, 2018: 765).

El enjambre concebido por Han supone que la información se produce, envía y recibe sin mediación o resignificación de los intermediarios. Ahora bien, Sergio Roncallo-Dow (2015) apunta que "los medios digitales no son meras plataformas de flujos inocuos de información" (307). Al respecto, indica que el problema no radica centralmente en los soportes de producción, sino en los modos de construir sentidos performativos.

Douglas Thomas y John Seely Brown (2011) y Ángel Pérez Gómez (2013), por su parte, coinciden en remarcar que los tipos de representación en el marco de la intermediación digital son cada vez más sofisticados y diversos. Desde la Teoría Social de la Comunicación, Jesús Martín Barbero (2003) hace su contribución a partir de la crítica al "mediacentrismo" y de una concepción no reproductivista de la información. Así, el autor reconoce la existencia de "mediaciones" (resignificaciones) por parte de los receptores cada vez que estos últimos se exponen a los medios. La mediación constituye, entonces, un lugar de atribución de sentido que el actor social le otorga al mensaje a partir de su experiencia; es decir, con quién lo hace, en qué situación social, en qué momento histórico. De ese modo, se crea un ámbito de encuentro entre los sistemas de producción hegemónica y las instancias de recepción de los usuarios massmediatizados, quienes, al mismo tiempo, son autores de procesos prolongados y extendidos de apropiación simbólica de la cultura dominante (Martín Barbero, 2003; Thompson, 1998, 2002).

\section{DEL OTRO LADO DEL ENJAMBRE}

Manuel Castells (1994, 1996), Alfonso Bustos Sánchez y César Coll Salvador (2010) y Ángel Pérez Gómez (2013), entre otros, reconocen la existencia de un nuevo entorno de riesgos desconocidos, pero también de posibilidades desconocidas a partir del espacio digital. En efecto, este permite la interconexión de comunidades virtuales concebidas como redes 
de lazos interpersonales que proporcionan sociabilidad, información, sentido de pertenencia e identidad social. A pesar de la sobreinformación y desinformación reinantes en la denominada era de la información -valga esta vez la redundancia- el empleo de la tecnología en forma razonable posibilita el intercambio de experiencias, así como también permite potenciar el pensamiento, en vez de destruirlo (Díaz, 2017).

En el presente apartado haremos una breve referencia a algunas manifestaciones sociales que, desde una interpretación no monolítica del espacio, cuestionan la conceptualización del enjambre como un ámbito reproductor de la cultura hegemónica o, por el contrario, ingenuamente libertario.

En un artículo sobre las prácticas de resistencia por parte de los actores sociales del pueblo mapuche, en particular aquellas generadas a partir de las posibilidades que brindan las tecnologías del espacio digital, Claudio Maldonado Rivera y Carlos del Valle Rojas (2013) analizan cómo la información y la comunicación pueden ser vectores de discursos alternativos o de resistencia. En coincidencia con Christine Hine (2004), los autores explican que para entender el proceso de cambio social y/o lucha que se puede generar en el entorno virtual, el análisis no debe situarse en la tecnología por sí misma, sino en los procesos de apropiación simbólica que llevan a cabo los sujetos. Así resulta que, mediante la incorporación de hipertextos a las redes sociales, en particular Facebook y Twitter, los mapuches construyen un Nosotros de enunciación en actitud de resistencia y, por esa razón, hábil para cuestionar el discurso dominante respecto al modo en que el Otro mapuche es representado socialmente.

En el marco de una competencia desigual entre medios mapuches y medios tradicionales hegemónicos, dichos actores sociales han sido capaces de conformar "una comunidad cohesionada en torno al sentido de la producción informativa, entendida como herramienta reivindicativa del/ para el pueblo mapuche" (Maldonado Rivera \& del Valle Rojas, 2013: 296). El espacio digital, entonces, les ha posibilitado a los productores mapuches ampliar sus canales de difusión y tener un registro de los usuarios que siguen 
o refuerzan sus relatos informativos. Como afirman Maldonado Rivera y del Valle Rojas, este hecho revela la potencialidad del ámbito comunicacional digital para construir sentido desde lo alternativo que lucha por constituirse en "alterativo", en contraposición a sistemas discriminatorios cimentados en la exclusión y la producción de estereotipos etno-raciales (301). ${ }^{2}$

Desde el campo de los Estudios Culturales, Stuart Hall $(1996,2017)$ entiende que la posición negociada del actor/receptor de mensajes reconoce la legitimidad de las definiciones hegemónicas, aunque, a su vez, las resemantiza en ámbitos más propios de un Nosotros identitario. Asimismo, mediante la operación de oposición, el sujeto registra y comprende los códigos dominantes, pero los decodifica de manera contraria, anclándolos en una interpretación cuestionadora del orden imperante. Estas dicotomías, como sabemos, resultan claramente identificables en las expresiones de los usuarios de internet, en buena medida autoidentificados como "lovers" y "haters".

A la luz del imperio de la conectividad, José van Dijck (2015) centra su atención en las interacciones sociales resultantes de nuevas formas de socialización que, en desmedro de una conexión propiamente humana, codifican la conectividad como comercialización de datos. Si bien su abordaje no se inscribe en el determinismo tecnológico, la autora cuestiona a quienes conciben que la tecnología de la información y la comunicación son ajenas a los intereses sociales que se consuman en un espacio caracterizado por la mercantilización automatizada. Por otra parte, van Dijck destaca que los entornos virtuales y las prácticas de los actores también se realizan en forma mutua, abriendo paso, de esa forma, a diferentes ámbitos de encuentro.

Algunas de las creaciones de sentido que se muestran en el espacio digital dan cuenta de resignificaciones percibidas en clave de amenaza cultural por su capacidad de tensionar el discurso de afirmación del Nosotros identitario inherente a cada cultura. En efecto, las tecnologías inteligentes del enjambre complejizan el acceso, procesamiento y expresión de la información y del

2 Se podría entender que se trata de "tácticas de negociación" (de Certeau, 1990) o de un uso de la tecnología de acuerdo con una racionalidad otra (Mattelart y Neveu, 2004). 
conocimiento y, de esa manera, participan en los procesos de socialización del sujeto y su consecuente comprensión de la realidad (Pérez Gómez, 2013).

En un estudio sobre los usos de la tecnología de la comunicación y de la información, David Morley explica que, en los últimos años, distintos gobiernos nacionales han intentado controlar el consumo de medios extranjeros mediante la prohibición de la televisión satelital o, de manera más reciente, mediante el monitoreo y control del acceso de la población a Internet. Para dar un ejemplo, cuenta que en Courcouronnes, ${ }^{3}$ Francia, el alcalde prohibió ubicar antenas satelitales en edificios altos donde vivía gran parte de su base electoral, alegando que esos dispositivos eran insalubres. La proscripción se implementó impulsada por el Frente Nacional de Francia, para el cual las antenas satelitales representaban una amenaza de la población inmigrante que habita en el territorio geográfico francés, pero que vive en un mundo de vida “islámico virtual” (Morley, 2016: 139). Esta participación de los inmigrantes en un espacio donde proyectarse y reafirmarse a partir de su propia identidad fue interpretada como una forma de "traición cultural" contra la nación francesa (140). ${ }^{4}$

En contrapartida, es innegable que en las dos últimas décadas han surgido incontables prácticas de resistencia gracias a las posibilidades que ofrece el espacio digital. Además de la convocatoria a marchas, protestas, campañas y diversas iniciativas de instituciones, grupos y movimientos sociales regionales, nacionales y globales, basta pensar en los avances de la educación a distancia y la posibilidad de realizar consultas médicas en lugares que resultan físicamente inaccesibles (por causas naturales, conflictos bélicos, etcétera.). En el ámbito local, un caso digno de mención lo constituye el Programa de Acompañamiento Universitario en Cárceles (PAUC), dependiente de la Prosecretaría de Derechos Humanos de la Universidad

3 Courcouronnes es un distrito del sur de París habitado principalmente por inmigrantes del norte de África.

4 Otro caso que cita Morley es el de la supuesta "reclusión" de los inmigrantes turcos en el espacio virtual de las emisoras transnacionales de Oriente Medio en Alemania, que algunos interpretan como un rechazo a participar plenamente en la cultura de ese país y, por ende, como posible motivo para negar la ciudadanía alemana. 
Nacional de La Plata (UNLP). Con el objetivo de promover y profundizar el estudio universitario en la población de personas privadas de la libertad, el proyecto se orienta a acompañar y reforzar las actividades de las distintas facultades que intervienen en instituciones carcelarias mediante el uso de aulas virtuales. ${ }^{5}$ Entendemos que estas prácticas representan expresiones de las fuerzas antitéticas tendientes a generar recorridos rizomáticos, capaces de crear y recrear constantemente estrategias para no subordinarse a los aparatos del poder (Deleuze y Guattarí, 1997). Como resultado de tales prácticas, el contexto carcelario puede transformarse, al menos en parte, en un nuevo ámbito de resocialización de acuerdo con las premisas fundantes del espíritu del derecho penal.

\section{A MODO DE CONCLUSIÓN}

Según la conocida tesis de Byung-Chul Han, el enjambre sumerge al ser humano en una crisis existencial que supone una nueva versión del "estadio del espejo", en la que el sujeto se incluye, pero deja de lado el reconocimiento de la alteridad. De ese modo, conculca el pensamiento complejo en la medida en que naturaliza la positividad inherente al mundo de vida digital (Han, 2014: 29).

Consideramos que dicho planteo abreva en idearios deterministas que ponderan en demasía la importancia de los medios tradicionales o sociales, reduciendo sensiblemente el poder del actor social o, de otro modo, conciben a este último como un seudoindividuo condenado a reproducir las estructuras hegemónicas, sin la posibilidad de decodificar otros sentidos, incluso insospechados.

Ciertamente, el espacio digital implica formas de dominación simbólica y sometimiento voluntario, funcionales a un sistema de vigilancia y un control ilimitado a la manera de un panóptico hipermoderno; pero, sin embargo, no

5 El espacio virtual de aprendizaje hace posible que los estudiantes accedan a los materiales de formación y se contacten con docentes y personal universitario (UNLP, 2018). 
solo se reduce a dichas manifestaciones. A modo de conclusión, sostenemos que el enjambre, al igual que cualquier componente de la sociedad, no supone proposición válida alguna de carácter absoluto o universal. En el espacio digital, los actores sociales llevan a cabo prácticas infinitamente diversas constituidas a partir de la introyección de un particular entramado simbólico compuesto por normas, costumbres, mitos, leyendas, valores, formas de ser del Estado y de la sociedad civil, entre otros elementos. A partir de ello, los actores conforman un Nosotros identitario social, individual e histórico (o anclado), con su correspondiente extrañamiento (y posibilidad de enriquecerse) frente al Otro diferente, tal como se desprende de algunos de los trabajos referidos en el segundo apartado del presente artículo.

Constituido desde el lenguaje, como está, en una determinada identidad social y personal, el ser humano dialoga con ambos lados del espejo digital. De esa manera, pone en acto el don característico de su especie: la facultad simbólica de crear sentido. Así es que el enjambre no puede someterlo plenamente sin más, ni tampoco le permite escapar totalmente a su influjo.

Por tal razón, no es posible entender el enjambre como una especie de significante que remite "a un significado"; por el contrario, se dan cita en él, "infinitos significados". Esto equivale a decir que el espacio digital es un ámbito más de la sociedad donde tienen cabida todo tipo de encodificaciones y decodificaciones, desde el recurrente y alienante "me gusta" hasta múltiples expresiones de colectivos galvanizados bajo el faro de la transformación social.

Cuando dejamos atrás la falacia de asumir a priori que por detrás de la palabra espacio existen realidades homogéneas, bien configuradas o estables, irrumpe el lenguaje como artífice de lo infinitamente diverso (Gadamer, 1998). La cuestión consiste en deconstruir el espacio-enjambre, ponerlo entre paréntesis, sin que ningún horizonte forcluya la posibilidad de descorrer los velos de la creación humana. Vale la pena terminar estas reflexiones con el epígrafe inicial -y profético- de Pascal: "Por el espacio, el universo me comprende y me devora como a un punto". Por el pensamiento, estamos de camino a comprenderlo. 


\section{REFERENCIAS}

Adorno, Theodor Ludwig W. y Max Horkheimer. Dialéctica de la Ilustración. Madrid: Ediciones Akal, 2007.

Berger, Peter. L. y Thomas Luckmann. La construcción social de la realidad. Buenos Aires: Amorrortu Editores, 2015.

Bourdieu, Pierre. Curso de sociología general 1. Conceptos fundamentales. Buenos Aires: Siglo XXI Editores Argentina, 2019.

El sentido social del gusto. Elementos para una sociología de la cultura. Buenos Aires: Siglo XXI Editores, 2011.

Bustos Sánchez, Alfonso y César Coll Salvador. "Los entornos virtuales como espacio de enseñanza y aprendizaje. Una perspectiva psicoeducativa para su caracterización y análisis", Revista Mexicana de Investigación Educativa, 15/44 (2010):163-184.

Castells, Manuel. La era de la información. Economía, sociedad y cultura. México: Siglo XXI Editores, 1996.

Nuevas perspectivas críticas en educación. Barcelona: Paidós, 1994.

Castoriadis, Cornelius. La institución imaginaria de la sociedad. El imaginario social y la institución. Buenos Aires: Tusquets Editores, 1993.

Corcuff, Philippe. Las nuevas sociologías. Principales corrientes y debates 1980-2010. Buenos Aires: Siglo XXI Editores, 2015.

de Certeau, Michel. La invención de lo cotidiano. México: Universidad Iberoamericana, 1990.

Deleuze, Gilles y Félix Guattarí. Mil mesetas. Capitalismo y esquizofrenia. Valencia: Pretextos, 1997.

Díaz, María Esther. Problemas filosóficos. Buenos Aires: Editorial Biblos, 2017

Foucault, Michel. La hermenéutica del sujeto. Buenos Aires: Altamira, 1996.

Gadamer, Hans-Georg. Arte y verdad de la palabra. Barcelona: Paidós Ibérica, 1998. 
Giddens, Anthony, La constitución de la sociedad. Bases para la teoría de la estructuración. Buenos Aires: Amorrortu Editores, 2011.

Giddens, Anthony y Philip. W. Sutton. Sociología. Madrid: Alianza Editorial, 2018.

Habermas, Jürgen. Perfiles filosóficos-politicos. Madrid: Taurus, 1993.

Hall, Stuart. Estudios Culturales 1983. Una historia teorética. Barcelona: Paidós, 2017.

"Encodificar/decodificar". Culture, Media, Language. Working Papers in Cultural Studies, 1972-79. Londres: Routledge \& The CCCS University of Birmingham, 1996. Recuperado de https:// comunicacionyteorias 1 .files.wordpress.com $/ 2009 / 10 /$ hall_s codificar_decodificar.pdf. Fecha de consulta: 1 de abril de 2019.

Han, Byung-Chul. La sociedad del cansancio. Barcelona: Herder Editorial S.L., 2017.

En el enjambre. Barcelona: Herder Editorial S.L., 2014.

Hardt, Michael y Toni Negri. Multitud. Guerra y democracia en la era del imperio. Barcelona: Debate, 2004.

Hine, Christine. Etnografia virtual. Barcelona: Editorial UOC, 2004.

Jullien, François. Las transformaciones silenciosas. España: Bellaterra Ediciones, 2010.

Del tiempo. Elementos de una filosofia del vivir. Madrid: Arena Libros, 2005.

Lefebvre, Henri. La producción del espacio. Madrid: Capitán Swing Libros S.L., 2013.

Maldonado Rivera, Claudio y Carlos del Valle Rojas. "Medios de comunicación y narrativas hipertextuales: lógicas del desplazamiento del 'conflicto mapuche' al espacio virtual", Andamios 10/22 (2013): 283-303.

Martín Barbero, Jesús, De los Medios a las Mediaciones. Colombia: Convenio Andrés Bello, 2003.

Martínez Novo, Rodrigo. "Del tiempo insostenible y del sentido del tiempo en las comunidades kichwa canelos", Desacatos 40 (2012):111-126. 
Mattelart, Armand y Érik Neveu. Introducción a los estudios culturales. Barcelona: Paidós, 2004.

Morley, David. "Pertenencias. Lugar, espacio e identidad en un mundo mediatizado". Pensar este tiempo. Espacios, afectos, pertenencias. Leonor Arfuch (ed.). Buenos Aires: Prometeo Libros, (2016): 123-158. Ordoñez Roig, Vicente. "De Big Brother a Big Data: reflexiones a propósito de Im Schwarm. Ansichten des Digitalen de Byung-Chul Han", Araucaria. Revista Iberoamericana de Filosofia, Política, Humanidades y Relaciones Internacionales 20/40 (2018):759-771.

Pérez Gómez, Ángel. Educarse en la era digital. Madrid: Ediciones Morata S. L., 2012.

Rawls, John. Teoría de la justicia. México: Fondo de Cultura Económica, 1993.

Roncallo-Dow, Sergio. "Muchedumbre, artes y política. Byung-Chul Han y las racionalidades comunicativas contemporáneas", Palabra Clave 18/2 (2015): 305-311.

Safranski, Rüdiger. Tiempo. La dimensión temporal y el arte de vivir. Barcelona: Tusquets Editores, 2017.

Schütz, Alfred y Thomas Luckmann. Las estructuras del mundo de la vida. Buenos Aires: Amorrortu editores, 2015.

Thomas, Douglas y John Seely Brown. A New Culture of Learning: Cultivating the imagination for a World of Constant Change. Lexington: Createspace, 2011.

Thompson, John Brookshire. Ideología y cultura moderna. Teoría crítica social en la era de la comunicación de masas. México D.F.: Universidad Autónoma Metropolitana, 2002.

Los media y la modernidad. Una teoría de los medios de comunicación. Barcelona: Paidós. 1998.

Tuan, Yin-Fu. Topofilia. Un estudio de las percepciones, actitudes y valores sobre el entorno. España: Editorial Melusina, 2007. 
Universidad Nacional de La Plata (UNLP). La UNLP refuerza su presencia institucional en cárceles de la región. (4 de diciembre de 2018). Universidad Nacional de La Plata (UNLP). Recuperado de: https:// unlp.edu.ar/pauc. Fecha de consulta: 6 de abril de 2019.

van Dijck, José. La cultura de la conectividad. Buenos Aires: Siglo XXI Editores, 2015.

Westphal, Bertrand. La cage des méridiens. La littérature et l'art contemporain face à la globalization. París: Minuit, 2016. "Aportes para un enfoque geocrítico de los textos". Espacios, imágenes y vectores. Desafíos actuales de las Literaturas Comparadas. en Mariano García; María José Punte y María Lucía Puppo (comps.). Buenos Aires: Miño y Dávila - Universidad Católica Argentina, (2015): 27-57.

Wittgenstein, Ludwig. Investigaciones filosóficas. México: Instituto de Investigaciones Filosóficas, Universidad Autónoma de México, 2003. 